\title{
EL COMPLIANCE COMO HERRAMIENTA DE PREVENCIÓN FRENTE A LA CRIMINALIDAD EMPRESARIAL UNA MIRADA DESDE LA CRIMINOLOGÍA MODERNA
}

\section{COMPLIANCE AS A PREVENTION TOOL AGAINST BUSINESS CRIME A VIEW FROM MODERN CRIMINOLOGY}

\author{
Mtro. Renzo Espinoza Bonifaz \\ Maestro en Derecho con mención en Ciencias Penales \\ Universidad de San Martín de Porres \\ aespinozab@usmp.pe \\ Perú
}

\section{SUMARIO}

- Introducción

- Compliance y responsabilidad de las personas jurídicas

- Aportes criminológicos para una mejor comprensión de la función del compliance

- Cómo debe ser un programa de cumplimiento eficaz

- Conclusiones

\section{RESUMEN}

Este trabajo de investigación busca analizar desde una visión criminológica el compliance como herramienta de prevención de la criminalidad en el seno de las personas jurídicas. Para ello, se recurre a las teorías criminológicas modernas de mayor trascendencia científica con la finalidad de comprender la razón de ser del compliance en el interior de una empresa y asegurar su mejor utilización como política criminológica estatal. Asimismo, se realiza un recuento histórico de su génesis a nivel internacional y de su incorporación en el ordenamiento jurídico peruano.

\section{ABSTRACT}

This research work seeks to analyze from a criminological view the compliance as a crime prevention tool within the legal entities. In order to do so, it is necessary to use modern criminological theories of greater scientific importance, in order to understand the raison d'être of compliance within a company, and ensure its best use as a state criminological policy. Likewise, a historical account of its genesis at the international level and of its incorporation in the Peruvian legal system is made.

\section{PALABRAS CLAVE}

Criminalidad empresarial, control social, criminología, programas de cumplimiento, prevención

\section{KEYWORDS}

Business crime, social control, criminology, compliance programs, prevention

\section{INTRODUCCIÓN}

El actual sistema penal peruano no ha podido disminuir la criminalidad existente en nuestro país. Esta, que no es solo la que se exhibe en los medios de comunicación, o que se investiga y juzga en el Ministerio Público y/o Poder Judicial, está afectando cada vez más nuestra estructura social y debilitando, sino destruyendo, la confianza de la población respecto a la eficacia del control social formal que detenta el Estado. 
Ante ello, es necesario reflexionar sobre cómo se está utilizando dicho poder estatal, es decir, no solo si se están emitiendo leyes penales que persigan evitar la comisión de delitos o sancionar drásticamente aquellos que se configuren, sino si estas leyes obedecen a políticas sustentadas en estudios criminológicos que permitan evaluar posteriormente si la puesta en vigencia de dichas leyes ha cumplido con el objetivo que se pretendía alcanzar o, en todo caso, qué correcciones resultarían necesarias para que así sea.

De esta manera, es evidente la necesidad de recurrir a la criminología como sustento científico de toda ley penal que se ponga en vigencia; de lo contrario, correríamos el riesgo de no saber si esta cumple la función para la cual ha sido publicada. Teniendo en cuenta que toda ley penal pretende controlar conductas humanas en concordancia con la función principal del sistema penal - que no es otra que la función de la pena-, no sería correcto, y menos legítimo, expedir leyes sin asegurar que las mismas puedan servir adecuadamente para dichos fines, pues ello generaría un control social formal desprestigiado por no cumplir cabalmente sus funciones.

Sin embargo, pese a lo señalado, observamos muchas veces que las leyes que se expiden se elaboran sin este previo análisis científico y se sustentan en la coyuntura social que se construye y se reconstruye desde los medios de comunicación, a lo que la criminología contemporánea ha denominado «criminología mediática». Esta manera de hacer leyes recurre a la creación de la realidad a través de subinformación y desinformación en concordancia con prejuicios y creencias.

Por ello, es imperante retomar el estudio científico de la realidad al momento de fabricar leyes penales. Para dicho fin, necesitamos de la ciencia del crimen, es decir, de la criminología, la cual, debido a su condición multidisciplinaria y método empírico, es capaz de brindarnos información legítima e íntegra sobre el origen, desarrollo, factores y causas del crimen con la finalidad de proponer programas de prevención eficaces, así como técnicas de intervención positiva al infractor.

Por otro lado, debemos tener en cuenta la evolución de la delincuencia de nuestros tiempos en relación con el daño e impacto social. Así, apreciamos un preocupante avance de la criminalidad organizada en nuestros días, la cual, de acuerdo con sus características propias, tiene una notable capacidad de adaptarse a las nuevas realidades sociales, identificando las fisuras en la organización social de un Estado que le permitan actuar y desarrollarse impunemente.

La globalización, sin lugar a dudas, es el escenario perfecto para la criminalidad organizada, pues las nuevas tecnologías entorpecen su detección y erradicación. En un mundo globalizado, los Estados normalmente reducen sus limitaciones normativas comerciales, permitiendo una ampliación de los mercados, con la finalidad de fomentar la libre circulación de los factores de producción. Este contexto otorga grandes sectores de operación a este tipo de criminalidad, que es sobre todo económica, pues su motivación normalmente es lucrativa.

El maestro español Jesús María Silva Sánchez (2001) señala en su célebre obra La expansión del derecho penal que:

Desde el punto de vista estructural, las características más significativas de la criminalidad de la globalización son dos. Por un lado, se trata de una criminalidad, en sentido amplio, organizada. Es decir, que en ella intervienen colectivos de personas estructurados jerárquicamente, ya sea en las empresas, ya incluso en la forma estricta de la organización criminal. La disociación que ello produce entre ejecución material directa $y$ responsabilidad determina, asimismo, que el resultado lesivo pueda aparecer significativamente separado, tanto en el espacio como en el tiempo, de la acción de los sujetos más relevantes en el plan delictivo. Desde el punto de vista material, la criminalidad de la globalización es criminalidad de sujetos poderosos, caracterizada por la magnitud de sus efectos, normalmente económicos, pero también políticos y sociales. Su capacidad de desestabilización general de los mercados, así como de corrupción de funcionarios y gobernantes, son rasgos asimismo notables. (p. 87)

Que este tipo de criminalidad sea organizada pone de manifiesto que se trata de estructuras 
con algún grado de jerarquización y que dificultan una investigación criminal, pues en no pocos casos se presentan problemas para determinar la atribución de responsabilidad penal, dada la separación espacio-temporal entre la decisión de los jerarcas y la ejecución del delito. A ello debe sumarse su gran capacidad económica, que les permite, incluso, desestabilizar las instituciones políticas de un Estado a través de la corrupción de sus funcionarios (Carnevali, 2010, p. 276).

Esta situación revela el inminente peligro que ostenta la criminalidad organizada, pues debilita las instituciones estatales hasta resquebrajar las bases de un Estado de derecho. En tal razón, es apremiante la adopción de medidas para defender las estructuras democráticas y sus medios de control a través de mecanismos eficaces, y no solo punitivos, para desarticular esta clase de organizaciones criminales. Muchas de estas son aparentemente personas jurídicas que incursionan en actividades económicas lícitas, y precisamente valiéndose de esta apariencia, cometen delitos que socaban profundamente el mercado y, por ende, la estructura social de todo Estado.

Ante ello, por razones de política criminológica, no podemos seguir enfrentándonos a este tipo de criminalidad con un derecho penal pensado para delitos de siglos pasados, pues la dogmática penal que lo sustenta no es adecuada para enfrentar estos nuevos retos. Y es que se trata de un derecho penal para delitos individuales que normalmente requieren de un resultado y lesión perceptibles a través de los sentidos. Por su parte, las organizaciones criminales son entidades poderosas que usualmente realizan actividades que ponen en peligro bienes jurídicos colectivos, que dañan el orden económico, la salud pública o el correcto funcionamiento de la administración pública de un Estado.

De esta forma, es evidente que la lucha contra este tipo de criminalidad requiere de instrumentos que anticipen oportunamente los daños sociales que producen los delitos cometidos por la organización criminal empresarial. No obstante, la adopción de dichas medidas demanda un análisis y sustento criminológico que garantice que dichas herramientas justifican adelantar la intervención punitiva del Estado. Ahí radica la importancia de la criminología, en el extremo que legitima la adopción de dichos instrumentos penales de manera científica y no improvisada.

\section{COMPLIANCE Y RESPONSABILIDAD DE LAS PERSONAS JURÍDICAS}

Como hemos señalado, dentro de esta criminalidad organizada puede incluirse a personas jurídicas que utilizan esta estructura legal para cometer delitos económicos con fines ilícitos de lucro. Y es que la confiabilidad de la sociedad en este tipo de estructuras organizadas fomenta el aprovechamiento de ellas, como de las leyes que las regulan. Por ende, las medidas que se establezcan para luchar en su contra deben ser efectivas para debilitarlas, sino extinguirlas, desde un plano económico.

Antes que nada, este trabajo de investigación no tiene la intención de examinar la pertinencia y legitimidad de introducir el principio societas delinquere potest en nuestra legislación penal; por el contrario, el objetivo de este artículo es analizar desde un enfoque criminológico las herramientas que se utilizan para enfrentar a la criminalidad desde la empresa.

Quedando claro tal propósito, es pertinente aclarar también que, si bien la Ley N. ${ }^{\circ} 30424$ - modificada por el Decreto Legislativo N. ${ }^{\circ} 1352$ - establece la responsabilidad administrativa de las personas jurídicas, todo parece indicar que es, por lo contrario, penal. Pues, se trata de responsabilidad por la comisión de delitos (cohecho activo, lavado de activos y financiamiento de terrorismo), bajo criterios de imputación que relacionan a una persona física que actúa en interés o para obtener una ventaja en favor de la persona jurídica, complementándose con la existencia o no de un modelo de prevención eficiente para evitar la comisión de delitos.

En este contexto cobra importancia el compliance, un dispositivo interno que las empresas implementan para cumplir con la normatividad vigente, así como para prevenir $\mathrm{y}$ detectar las infracciones legales que se produzcan dentro de las mismas o como parte de las actividades que estas realizan (Wellner, 2005 , p. 501). Tiene como propósito tanto la individualización de los ámbitos de riesgo para el ente en cuanto a la posible comisión de delitos, a modo de prevenirlos, como también disponer de mecanismos de actuación 
y de procedimientos a seguir por quienes se encuentran ya sea en posición superior o subordinada (Carnevali, 2010, p. 300).

Contar con un programa de cumplimiento puede eximir de responsabilidad a la persona jurídica; sin embargo, esto no ocurre automáticamente, pues existen ciertas condiciones, ahora legales, que deben ser verificadas para conceder tan importante beneficio. La primera de estas condiciones es la verificación por parte de la autoridad judicial de que el programa de cumplimiento resulta eficiente, es decir, que no es una simple fachada implementada para dar la apariencia de que la organización ha previsto los riesgos en los que podría incurrir $y$ que ha establecido los procedimientos necesarios para su prevención y detección. La segunda condición es la necesidad de que el programa se ajuste a los modelos de prevención establecidos por el legislador, los mismos que establecen el contenido concreto que será exigido por la autoridad judicial al momento de determinar la eficacia del compliance.

Por su parte, la tercera y última condición radica en que el programa supone, al menos en parte, la privatización de la función pública en cuanto al control de la criminalidad. Para ello, se exige a la empresa que detecte e investigue las posibles infracciones jurídicopenales que han tenido lugar en su seno, e incluso las conmina a aportar los resultados de la investigación interna a una investigación fiscal. Aquí, lo preocupante es la posibilidad de que en estas investigaciones internas no se cumplan de manera irrestricta las garantías de un debido proceso.

Por estas razones, es conveniente constituir dentro de las organizaciones departamentos de cumplimiento que cuenten con un procedimiento en el que se establezcan de manera clara los derechos y obligaciones de los encargados de las investigaciones internas, así como las garantías esenciales que gozan las personas sometidas al proceso de investigación, las cuales deberán ser similares a las garantías procesales establecidas en la Constitución, con la finalidad de otorgar legitimidad al programa de cumplimiento adoptado.

De esta manera, viendo la trascendencia jurídico-penal que ostenta esta herramienta de prevención en personas jurídicas, es necesario analizar y sustentar su legitimidad como instrumento del sistema jurídico penal desde un enfoque criminológico. La finalidad es garantizar que su adopción haya sido una correcta decisión legislativa $\mathrm{y}$, a la vez, dotar de información científica válida que permita realizar las correcciones normativas necesarias en el devenir de su aplicación en la realidad.

\section{APORTES CRIMINOLÓGICOS PARA UNA MEJOR COMPRENSIÓN DE LA FUNCIÓN DEL COMPLIANCE}

A través de los programas de cumplimiento, las personas jurídicas se organizan para cumplir las leyes y regulaciones que les concierne obedecer. Sin embargo, estos se vuelven ineficaces cuando se limitan a definir los procedimientos y las políticas únicamente con el afán de tener formalmente en un papel un modelo de prevención, sin existir el compromiso de generar una cultura de cumplimiento en la persona jurídica. Dicha cultura corporativa debe promover la integridad, como conducta ética, en todas las personas que conforman la persona jurídica. Si concebimos los programas de cumplimiento tan solo como una obligación legal a la que toda persona jurídica debe someterse por encontrarse dispuesta en una ley, será solo una exigencia formal más a la que toda organización deba sujetarse sin reparar en su verdadera función.

En este sentido, más que asegurar que las personas jurídicas se ajusten al ordenamiento jurídico que les corresponde acatar, estos programas tienen por finalidad prevenir la comisión de delitos en el seno de la organización. Por ello, es claro que existe un traslado de la función preventiva que le corresponde al Estado hacia ellas. De esta manera, su éxito radica en que pueda frustrarse la posible comisión de delitos desde las personas jurídicas. Siendo ello así, se debe analizar cuál es el sustento científico de esta institución jurídica desde una perspectiva criminológica con la finalidad de comprender mejor su origen y finalidad.

\section{Un poco de historia}

Debemos remontarnos a mediados de los años sesenta, cuando la Comisión Nacional del Mercado de Valores de los Estados Unidos de América descubrió que más de 400 compañías estadounidenses participaron en pagos ilegales a funcionarios públicos o partidos políticos 
en el extranjero. Es en aquel momento que puede situarse el origen del compliance pues, ante dicho descubrimiento, el Senado aprobó en diciembre de 1977 la Ley de Prácticas Corruptas en el Extranjero, prohibiendo los pagos ilegales a funcionarios extranjeros y exigiendo a las compañías cotizadas registrar todas las transacciones con sistemas de control interno adecuados.

Posteriormente, ante el nuevo contexto de libre circulación de capitales de los años noventa, las disímiles normatividades entre los países generaban ventajas competitivas para las compañías que continuaban realizando pagos ilegales. Es cuando se produjo un nuevo compliance, con la Convención para Combatir el Cohecho de Servidores Públicos Extranjeros en Transacciones Comerciales Internacionales de la Organización para la Cooperación y el Desarrollo Económico (OCDE) de 1997, mediante la cual los gobiernos suscriptores se comprometían a implementar una legislación que penalizara el soborno de un funcionario público extranjero.

Unos años antes, en 1991, la Comisión de Sentencias de los Estados Unidos publicó un manual de instrucciones con la finalidad de unificar los criterios en las resoluciones judiciales respecto a los crímenes cometidos por las corporaciones. Entre las disposiciones se establecía la necesidad de contar con un programa de cumplimiento normativo y de acciones para evitar la comisión de delitos como factores que puedan atenuar o evitar la condena de la compañía. A raíz de ello surge la figura del jefe de Ética y Cumplimiento, y muchas corporaciones adoptaron programas de cumplimiento. Además, los manuales de instrucciones sirvieron de ejemplo para muchos países al momento de legislar en materia anticorrupción y cumplimiento normativo.

Asimismo, el Comité de Organizaciones Patrocinadoras de la Comisión Treadway, formado por cinco asociaciones estadounidenses de auditoría y rendición de cuentas, publicó en 1992 un manual de marco de referencia integrado para el control interno de las corporaciones, el cual sirvió de modelo para el diseño, implementación, seguimiento y evaluación de controles internos.

Posteriormente, en el 2002, se expidió la Ley Sarbanes-Okley con el propósito de prevenir la falsificación del valor de las empresas en Bolsa, los fraudes y los riesgos de bancarrota; sin embargo, se comprobó que el solo hecho de que las corporaciones tengan programas de cumplimiento no era suficiente. Un caso como el de Enron fue la evidencia para entender que era necesario internalizar la cultura del cumplimiento normativo en toda empresa y, además, asegurar una supervisión efectiva de los programas de prevención internos.

\section{El compliance en el ordenamiento jurídico peruano}

En nuestro país, se expidió la Ley N. ${ }^{\circ} 27963$ el 12 de abril de 2002, estableciéndose que, para impedir o descubrir actos de lavado de activos, los sujetos obligados deben implementar un sistema de prevención y detección de actividades de lavado de activos en su ámbito específico de actuación.

La obligación de implementar el sistema de prevención y detección que la referida ley exige recae sobre el directorio de la empresa. Incluso, si es que se trata de una empresa con una organización compleja, se debe nombrar a una persona con estatus directivo para que se encargue de la implementación, funcionamiento y mejora del sistema de prevención y detección. La ley califica a este directivo como un oficial de cumplimiento; de ahí que se pueda decir que este sistema de prevención y detección de lavado de activos constituye un programa de cumplimiento normativo sectorial (García, 2014, p. 76). Además, la ley en mención implantó parámetros que deben ser incorporados en los modelos de prevención, estableciendo asimismo la sanción que se impondrá en caso de incumplimiento.

El 15 de octubre de 2005, el sector ambiental reguló modelos de prevención mediante la Ley N. ${ }^{\circ} 28611$, Ley General del Medio Ambiente, estableciendo en el artículo VI del Título Preliminar que toda persona tiene el deber de contribuir a una efectiva gestión ambiental con la finalidad de prevenir, vigilar y evitar su degradación. En concreto, las empresas cuya actividad puede generar algún impacto al medio ambiente deben adoptar medidas de prevención de riesgos y daños para preservarlo y protegerlo.

Luego, otro sector en el que el Estado ha dispuesto la obligación de las empresas de adoptar un 
programa de cumplimiento normativo es el de seguridad y salud en el trabajo. Así, el 20 de agosto de 2011 se publicó la Ley N. ${ }^{\circ} 29783$, Ley de Seguridad y Salud en el Trabajo. Esta impone la obligación a los empleadores de implementar medidas de cumplimiento normativo del sector. Además, establece una serie de principios sobre los cuales se basa, como el deber de prevención, el de responsabilidad del empleador y el deber de protección. Respecto a los deberes de prevención y protección, se señala que el empleador tiene la obligación de prevenir los riesgos de la actividad que realiza para la seguridad y salud de los trabajadores. Para ello, será necesario que cuente con medios y condiciones que aseguren que la actividad realizada por los trabajadores se desarrolla en un ambiente seguro y saludable.

En atención al principio de responsabilidad, es el empleador quien asume los costos de implementación de un programa de cumplimiento normativo y quien asume la responsabilidad por no haber implementado este programa si, como consecuencia de ello, el trabajador sufriera un accidente en el desempeño de su actividad.

De acuerdo con lo establecido por la norma, se trata de que las empresas adopten programas de cumplimiento normativo en el sector de seguridad y salud en el trabajo. Para ello, deberá tenerse en cuenta la actividad que cada empresa realiza. Conforme lo establece el artículo 2, la ley es aplicable a todos los sectores económicos y de servicios; sin embargo, el hecho de que la empresa adopte un programa de cumplimiento estricto y contundente dependerá de la complejidad de la organización y de la actividad en sí, ya que existen actividades más riesgosas que otras.

Por otro lado, es importante mencionar el artículo 3 de la ley en el que se establecen parámetros mínimos para la prevención de los riesgos laborales y se acepta que los privados establezcan libremente niveles de protección mayores que mejoren la situación de los trabajadores. No obstante, el Estado considera que la obligación legal de adoptar un sistema de cumplimiento normativo no es suficiente para garantizar la seguridad y salud de los trabajadores.

Finalmente, la aparición de nuevos escándalos de corrupción corporativa en nuestro continente generó que las autoridades gubernamentales de nuestro país decidan introducir el compliance en los sectores más sensibles de toda empresa para permitir la normalización de la función del cumplimiento normativo a nivel corporativo.

Por ello, el 21 de abril de 2016, se aprobó la Ley N. ${ }^{\circ} 30424$, cuyo objeto es regular la responsabilidad administrativa de las personas jurídicas inicialmente por el delito de cohecho activo transnacional previsto en el artículo $397^{\circ}$-A del Código Penal, lo cual ha sido posteriormente ampliado mediante el Decreto Legislativo N. ${ }^{\circ} 1352$, incluyendo los delitos de cohecho activo genérico y específico, lavado de activos y financiamiento de terrorismo.

Referente a los modelos de prevención, la ley establece que una persona jurídica no es responsable administrativamente - por los delitos antes mencionados - si esta hubiera adoptado e implementado en su organización, con anterioridad a la comisión del delito, un modelo de prevención adecuado a su naturaleza, riesgos, necesidades y características, consistente en medidas de vigilancia y control idóneas para prevenir el delito en mención o para reducir significativamente el riesgo de su comisión. En el artículo $17^{\circ}$, inciso 2 se establecen las características y elementos que debe presentar el modelo de prevención o programa de cumplimiento.

\section{Del control estatal al control privado}

El compliance exige que las empresas, en cierto modo, asuman una tarea pública y que se autorregulen con el fin de ponerse al lado del Estado en la tarea de controlar nuevos riesgos, proteger accionistas o consumidores, o evitar hechos delictivos. Entonces surge un nuevo pacto entre Estado y poder corporativo, donde a cambio de los beneficios derivados de la responsabilidad limitada, y de la cada vez mayor libertad económica, este se compromete a cumplir determinados fines públicos.

Si este nuevo pacto se contempla desde una perspectiva mundial, se evidencia con claridad que la responsabilidad de las personas jurídicas forma parte del buen gobierno global, de la global governance. Desde el punto de vista empresarial, las nuevas responsabilidades públicas representan de algún modo el colofón de la denominada responsabilidad social de la empresa. En este sentido, ¿cuál es la razón que impulsa al Estado a firmar este pacto, 
comprometiéndose a no sancionarlas a cambio de que controlen y prevengan con eficiencia los riesgos de naturaleza penal que puedan surgir en su interior? Sin lugar a dudas, una de las razones es su dificultad para identificar en las complejas estructuras organizacionales de las corporaciones los posibles delitos que pudieran cometerse.

No toda persona jurídica es compleja por el hecho de serla, por lo que es correcto que de lege ferenda se establezca que los modelos de prevención son exigibles a personas jurídicas que resultan complejas por sus características especiales.

\section{La persona juridica como unidad ecológica económica}

Observando a la persona jurídica como una unidad ecológica económica $-\mathrm{y}$ no en referencia a un enfoque ecológicobiológico tradicional, sino a uno según la «teoría ecológica» impulsada por la Escuela de Chicago, cuna de la moderna sociología americana-, podemos afirmar que en el seno de toda persona jurídica existen sectores más sensibles desde donde se produce criminalidad.

La «teoría ecológica», acudiendo a los conceptos de desorganización y contagio inherentes en cualquier estructura corporativa compleja $\mathrm{y}$, sobre todo, admitiendo el debilitamiento del control social formal que en estos tienen lugar. Además, la falta de liderazgo dentro de la empresa, lo superficial de las relaciones interpersonales en ella, el alto dinamismo de las transacciones comerciales, las crisis de valores en el interior de las corporaciones, el culto a la riqueza y la obtención de beneficios personales por sobre los colectivos, etc., evidencia la creación de un ente desorganizado y criminógeno. Este ambiente potencialmente criminógeno propaga inevitablemente un clima de vicio y corrupción contagioso que le corresponde reducir a los programas de cumplimiento, o mejor llamados «modelos de prevención». Creemos que ello solo se conseguirá si se alinean los objetivos de la persona jurídica con el cumplimiento de la normativa jurídica.

Debemos ir más allá del cumplimiento formal, pues no es suficiente que el modelo de prevención se adecúe formalmente a los requisitos que establecen las leyes penales, sino que también debe crear en la persona jurídica el compromiso de respetar y cumplir la ley.

Teniendo como referencia la experiencia estadounidense, los mecanismos de supervisión, vigilancia, control e imposición de sanciones no son suficientes para evitar que los empleados cometan delitos. La imposibilidad de detectar todos los comportamientos delictivos a través de estos, sumados a las diferentes interpretaciones a las que están sujetas las leyes y la imposibilidad de regular todas las situaciones, demuestra que determinadas situaciones requerirán la capacidad de evaluación y decisión de los actores implicados.

Por tanto, si estos actores, que son quienes finalmente ponen en práctica los modelos de prevención, no han internalizado correctamente la cultura del compliance de la organización a la que pertenecen, dicho programa no tendrá éxito. Utilizar como eje central de los modelos de prevención el miedo de los integrantes de la organización a ser sancionados por el incumplimiento del mismo, conllevará lamentablemente a que actúen conforme a dichos programas solo cuando tengan temor a ser descubiertos, continuando con sus malas conductas cuando sepan de la inexistencia de control.

En este sentido, y dentro de esta incorrecta comprensión de lo que debe ser un modelo de prevención eficaz, se considera un sistema enérgico de vigilancia y control que puede generar un clima laboral hostil y de desconfianza dentro de la organización, pues cada colaborador de la persona jurídica será visto como sospechoso, lo cual desencadenará una disminución de su productividad, iniciativa y compromiso con el cumplimiento de la ley. Además, el miedo a ser sancionado puede llevarlo a no denunciar una mala conducta e, incluso, a encubrirla hasta cometer un delito, lo cual dificultaría la prevención de delitos como finalidad de los programas de cumplimiento.

\section{Psicología comunitaria aplicada a la persona juridica}

La psicología comunitaria, de enfoque ambientalista, con connotaciones ecológicascriminológicas, reclama un papel activo de las pequeñas comunidades y estimula la acción 
de las instituciones mediadoras entre la vida privada y la esfera pública, y propugna un nuevo modelo de «intervención» (GarcíaPablos, 1994, p. 192).

Consciente del impacto negativo que las instancias oficiales de un sistema legal (policía, tribunales, administración penitenciaria, etc.) ocasionan en su intento de abordar el problema criminal, la psicología comunitaria opta por una vía realista de intervención sugiriendo el fortalecimiento de las instituciones intermedias que median entre la privacidad del ciudadano y la vida pública, así como la de determinados «centros sociales» (familiares y comunitarios) decisivos en la socialización del individuo y en la deseable participación más eficaz de este en los problemas de la comunidad (GarcíaPablos, 1994). Entre estos «centros sociales» podemos incluir a las personas jurídicas, pues constituyen espacios donde las personas socializan a través del trabajo utilizando no solo sus conocimientos técnicos y/o profesionales, sino, sobre todo, los valores adquiridos en el desarrollo de su personalidad.

Son postulados de la psicología comunitaria que la intervención ha de tener un impacto preventivo, incidiendo en aquellos lugares en donde se presenta el problema; que no se conforma con la reforma personal del individuo, sino que pretende producir cambios institucionales, por entender que una reorganización ambiental incide significativamente en la conducta de los miembros o individuos de la institución; que los programas de intervención deben contemplar variables de tipo legal, sociológico, político, económico y organizacional (García-Pablos, 1994, p. 193).

De esta manera, para que un programa de cumplimiento funcione, es fundamental la participación activa de los colaboradores en la definición de los valores corporativos; de lo contrario, mostrarán su desacuerdo, pudiendo llegar a boicotear estos valores y generar una falta de legitimidad en el sistema de prevención. En este sentido, no se deben exigir conductas inalcanzables ni sobredimensionar las sanciones a imponerse.

\section{Criminologia critica y criminalidad de "cuello blanco"}

No hay que perder la perspectiva respecto a la normalidad $\mathrm{y}$ funcionalidad del crimen.
Las «teorías estructural-funcionalistas» de la criminología moderna han demostrado que el crimen es un acto normal que no se origina en una patología individual o social, sino en el normal y regular funcionamiento de todo orden social.

El sociólogo francés Émile Durkheim, mediante su «teoría de la anomia», plantea que el crimen, como conducta irregular, debe analizarse no en función de supuestas anomalías del sujeto, sino de las estructuras de la sociedad, por ejemplo, las personas jurídicas. Además, el delito es ubicuo, puede producirse en cualquier estrato de la pirámide social y en cualquier modelo de sociedad. Añade Robert Merton que la «anomia» no solo evidencia la crisis de valores por circunstancias sociales (desarrollo económico vertiginoso, el proceso de globalización con todas sus implicancias), sino, sobre todo, evidencia el vacío que se genera cuando los medios socio-estructurales no sirven para satisfacer las expectativas culturales de la sociedad.

De esta manera, quienes notienen oportunidades para satisfacer sus necesidades se ven forzados a la comisión de conductas irregulares para conseguirlas. Por necesidades debemos no solo referirnos a las básicas, pues, de acuerdo con la teoría de la jerarquía de las necesidades de Abraham Maslow, todo ser humano va estableciéndose nuevas necesidades conforme va satisfaciendo cada clase de ellas; así, va de la necesidades fisiológicas a las de seguridad, luego a las de aceptación social, posteriormente a las de autoestima $y$, finalmente, a las de autorrealización. Así, resulta claro afirmar que no solo las personas de condición económica precaria cometen conductas irregulares, pues el ser humano, siempre se plantea nuevas necesidades por satisfacer.

En los años treinta, Edwin Sutherland inició sus indagaciones sobre la criminalidad de «cuello blanco», la delincuencia económica y profesional, estudios de transcendental importancia para esta investigación. Concluyó que la conducta desviada no puede imputarse tan solo a los individuos de la clase deprimida o baja, alegando problemas de disfunciones o inadaptación que ellos tendrían. Afirmó, además, que el aprendizaje de valores criminales puede ocurrir en cualquier nivel social. Según el sociólogo estadounidense, la conducta criminal no se hereda ni se inventa, 
sino que se aprende mediante el contacto con valores, hábitos $\mathrm{y}$ actitudes criminales en los procesos de interacción comunicacional normales de los individuos. Como es lógico pensar, dicho aprendizaje se puede dar en el seno de una persona jurídica.

De esta manera, Sutherland aporta una teoría capaz de fundamentar la criminalidad de las clases medias y privilegiadas ofreciendo un cambio de paradigma; señala que el crimen no procede de la desorganización social, sino de la organización diferenciada y del aprendizaje.

\section{Cambio de paradigma en el control social}

Ahora bien, si todo individuo posee el potencial necesario para realizar conductas desviadas en los diversos ámbitos que ofrece la sociedad - como las personas jurídicas-, ¿por qué muchos optan por ceñir su comportamiento a las expectativas normativas sociales? Para la criminología clásica, la respuesta se encuentra en el miedo al castigo; por el contrario, la criminología contemporánea nos brinda otra explicación.

Lo que sucede es que el individuo evita conductas irregulares debido a que se siente integrado a la comunidad u organización social de la que es parte, y tiene una razón positiva para comportarse correctamente. En su «teoría del arraigo social», Travis Hirschi señala que el apego y consideración hacia sus semejantes, el compromiso e identificación con los valores sociales, la participación en actividades sociales, y las creencias y conocimientos del individuo, constituyen los lazos o vínculos que lo unen con la organización social que conforma. El debilitamiento de estos factores dejará despejado en el individuo el camino al crimen.

La ética de todo integrante de una persona jurídica es el elemento indispensable que necesita el compliance para que sea efectivo. Para lograrlo, se requiere implicar a los colaboradores en el proceso de construcción de los principios y valores corporativos que guiarán la toma de decisiones y las actuaciones. Esto permitirá comprender el razonamiento que justifica dichos principios de conducta, generando motivación interna para cumplirlos (surge del propio individuo, y no del temor a una sanción).
En su conjunto, esta situación crea una cultura de confianza y forja una atmósfera propicia para que los colaboradores propongan iniciativas que permitan mejorar las prácticas existentes, avanzando hacia la excelencia. Hay facilidad para denunciar inconductas funcionales a los superiores, pues se incrementa el compromiso y la identificación con los valores de la corporación, ya que, al sentirse apoyado y escuchado, desarrolla recíprocamente dicha confianza.

Pero lo más importante es que no existen diferencias entre los valores propios del colaborador y los de la organización, pues estos son compartidos, por lo que desaparecen eventuales disonancias cognitivas y conflictos internos. Ello estimula el sentido crítico, y los colaboradores son capaces de cuestionar las malas prácticas, identificando y resolviendo contextos que planteen conflictos de intereses. Así, el compliance es parte de la identidad y de la responsabilidad individual y colectiva, pues se observa como un aspecto positivo del trabajo diario. Además, el colaborador se siente autorrealizado cuando ajusta su comportamiento a los programas de cumplimiento.

Todo lo dicho provoca que los modelos de prevención no se limiten a cumplir los estándares mínimos, sino que busquen alcanzar la excelencia, pues el comportamiento ético se autorreproduce en la organización, creándose una sinergia que se extiende en todos sus sectores. Permite también la existencia de una cultura del valor y no del miedo mediante restricciones.

Sin lugar a dudas, para lograr todo lo descrito se requiere de un mayor esfuerzo que para imponer un sistema de vigilancia y control, que en realidad no es más costoso. Como beneficio adicional, esta cultura corporativa genera un excelente clima laboral, lo cual, en concordancia con la «teoría ecológica» ya explicada, forja valores sólidos y permanentes, no eximiendo a los líderes de la organización a siempre estar atentos a las sugerencias de los colaboradores de la corporación y a ser asertivos con ellos.

No obstante, resulta oportuno mencionar las «técnicas de neutralización» propuestas por Gresham Sykes y David Matza. Según estas, pese a que internalicemos los valores 
desarrollados por una organización, podemos desarrollar ciertas técnicas capaces de autojustificar conductas irregulares o desviadas de los patrones establecidos. Así, resultan ser mecanismos de defensa con los que el transgresor neutraliza su responsabilidad y legitima su conducta, es decir, se convence de que es correcto lo que está haciendo. Estas técnicas están relacionadas íntimamente con la «teoría de la asociación diferencial» planteada por Sutherland, pues sirven de base para que el transgresor justifique $\mathrm{y}$ aprenda hábitos desviados.

La primera de ellas es «la negación de la responsabilidad». Mediante esta técnica, el infractor se convence de que no es responsable de lo que hace, pues la responsabilidad es de otros; su conducta es causa de fuerzas ajenas a su voluntad que están fuera de su control. La siguiente es «la negación del daño»; el transgresor considera que su conducta es leve o nula, y que, pese a que contraviene la ley, no genera daño alguno. Inclusive, el foco de atención puede ser desplazado a la conducta de otros, quienes pueden estar realizando la misma conducta del infractor. Al respecto, pueden surgir frases que forman parte del folclore cultural — «el que roba a un ladrón tiene cien años de perdón»- para justificar, por ejemplo, la evasión de tributos, argumentando que el Estado se apropia indebidamente de los impuestos que pagan los ciudadanos; entonces, el no pagarlos no generará ningún daño al interés público.

Otra de ellas es «la negación de la víctima»; en uno de los supuestos, el infractor entiende que la víctima de la conducta desviada que realiza la merece, llegando a pensar inclusive que la víctima es realmente quien es el transgresor. En otro, debido a la naturaleza de la infracción, resulta difícil individualizar a la víctima. Esto ocurre sobre todo en el caso de los delitos en agravio de la sociedad o del Estado; al ser supraindividuales, es difícil identificar quién realmente resulta perjudicado.

En el caso de los delitos que se podrían cometer en el seno de una persona jurídica - dando lugar a la sanción de esta-, encontramos actualmente delitos de corrupción activa, lavado de activos y financiamiento del terrorismo. Una característica común de todos ellos es que son ilícitos que afectan bienes jurídicos colectivos, debilitándose, por ende, el conocimiento de la existencia de la víctima, dando por ello la posibilidad de que los infractores puedan utilizar la técnica de neutralización referida recientemente.

Otra técnica es «la condena a quien condena»; el desviado transfiere la responsabilidad de su comportamiento a quienes reprueban su conducta, aduciendo que son infractores encubiertos o que se trata de una persecución injusta. Lo que busca el infractor es desacreditar a quien pretende castigarlo argumentando que no tiene legitimidad moral para hacerlo.

Finalmente, la última de ellas es «la apelación a lealtades superiores». Aquí se presenta un problema de roles, pues el infractor tiene un dilema entre cumplir las normas socialmente aceptadas o las impuestas por su organización o comunidad particular. Una variable a tener en cuenta es la percepción que tienen los colaborados de la organización respecto a su líder, es decir, los directivos y altos funcionarios de las personas jurídicas, que gozan de prestigio social y son vistos como hombres honorables y exitosos que conducen su vida de manera correcta. Por tanto, las órdenes que puedan impartir, aun siendo desviadas o ilícitas, pueden inducir a los colaboradores a plantearse el dilema antes señalado.

Es en esta disyuntiva que resulta importante la existencia de la cultura corporativa moralmente sólida y basada en la integridad, por lo cual se debe buscar la excelencia operacional a lo largo de toda la organización. Ello se puede lograr si se tienen claros los objetivos del compliance y si se identifican los comportamientos anómalos internos y las influencias externas que afectan el desempeño íntegro de la corporación, la promoción de valores basados en la transparencia y el compromiso entre los diferentes departamentos de la corporación. Esta situación será la que garantice la continuidad y sostenibilidad de la organización y su cumplimiento normativo. De lo contrario, la percepción de que se están produciendo comportamientos fraudulentos puede llevar a otros colaboradores a autojustificar sus malas prácticas y contagiar esa conducta a los demás miembros de la organización. Así, se dará cabida a la utilización de las «técnicas de neutralización» explicadas. 


\section{CÓMO DEBE SER UN PROGRAMA DE CUMPLIMIENTO EFICAZ}

Los programas de cumplimiento tienen el fin mediato o trascendente de generar en la persona jurídica una cultura de cumplimiento basada en la integridad de sus colaboradores, logrando que ellos internalicen valores sólidos. No obstante, su fin inmediato persigue alinear los objetivos de la corporación con la observancia de la normativa jurídica respectiva.

Debemos ser enfáticos en señalar que no se trata de normar lo ya normado a través de los programas de cumplimiento. Existen leyes penales de obligatorio cumplimiento para todos los ciudadanos y, por tanto, también para los colaboradores que integran la persona jurídica.

Lo importante del compliance es saber utilizarlo como una herramienta para promover hábitos éticos en el seno de toda empresa, ya que si solo lo aplicamos para «cumplir» no se tendrá el éxito deseado. Las leyes penales también se deben "cumplir», pero muy pocas personas lo hacen.

Para que dicho programa de cumplimiento sea eficaz, es decir, que utilice los mínimos recursos y logre sus objetivos, se requiere de un constante trabajo de perfeccionamiento de su contenido y procedimientos. Por ello, todo programa de cumplimiento debe estar asentado en tres columnas fundamentales: prevención, detección y reporte, y resolución.

\section{Prevención}

Como ya hemos señalado en los apartados anteriores, el éxito del programa de cumplimiento radica en el hecho de configurase como una herramienta idónea de anticipación de las posibles conductas desviadas producidas en el seno de las personas jurídicas en el ámbito privado. Por tanto, esta etapa debe buscar impedir la comisión de delitos por parte de los colaboradores de la empresa.

Como primer punto, se deben identificar las actividades y sectores de la empresa en donde se pueden llegar a cometer delitos. Una vez evaluados estos riesgos, se diseñarán e implementarán los protocolos y procedimientos que permitan la prevención de delitos en dichos sectores. Para tal fin, se elaborará un código de conducta ética, un protocolo de políticas para la toma de decisiones, un procedimiento de vigilancia y control con un sistema de incentivos y sanciones, etc.

Debemos tener presente que el éxito de los protocolos y procedimientos dependerá de la capacitación efectiva de las áreas encargadas de aplicarlos y velar por su observancia. Estas áreas, a su vez, deben sensibilizar a todos los colaboradores de la empresa sobre la importancia del cumplimiento, sobre todo a los consejeros y directivos, pues, siendo líderes de la corporación, tienen influencia directa en las actitudes de sus colaboradores. Solo a través de la práctica diaria de hábitos positivos se logrará generar una cultura corporativa basada en la integridad ética.

Un factor importante en este sentido es comunicar a todos el comportamiento positivo de algún colaborador de la empresa, como también incentivarlos a la participación dentro de la corporación, ya sea para plantear sus dudas o brindar una sugerencia respecto a los protocolos y procedimientos adoptados. Hemos señalado anteriormente que es un componente trascendental escuchar a los colaboradores de la empresa al momento de establecer los valores corporativos. Solo de esta manera se puede conseguir una identificación real con los mismos. De igual forma, es recomendable establecer políticas de contratación y promoción de los colaboradores basadas en méritos, pues crearán un clima laboral altamente deseable.

\section{Detección y reporte}

Esta etapa es la más importante del compliance, pues la persona jurídica será responsable de aquellos delitos que fueron posibles debido a una omisión de sus deberes de supervisión, vigilancia y control. No obstante, si la empresa demuestra que el programa de cumplimiento adoptado es idóneo para detectar y reportar oportunamente dichos delitos, quedará exenta de responsabilidad.

Para localizar e identificar las zonas en donde se puede producir un incumplimiento por comportamientos irregulares de los colaboradores, se requiere implementar una oficina de cumplimiento que monitorice la adecuación de las actividades empresariales al programa de cumplimiento adoptado. Esta oficina puede establecer un canal de denuncias, confidencial y anónimo, que 
reciba noticias sobre conductas indebidas, infracciones y posibles comportamientos que generen responsabilidad penal, disponible tanto para colaboradores como para clientes de la persona jurídica.

Los procedimientos de investigación iniciados a partir de las denuncias recibidas deben permitir esclarecer el suceso referido respetando las garantías de presunción de inocencia, derecho de defensa, legitimidad en la obtención de la prueba, etc., pues en todo momento se debe velar por el derecho fundamental al debido proceso del colaborador involucrado en dicho procedimiento.

Por otro lado, se debe revisar constantemente el programa de cumplimiento para localizar posibles fallas y corregirlas. Esto permitirá medir el desempeño del programa en relación con los objetivos establecidos. Finalmente, se deben obtener resultados concretos, pues un programa de cumplimiento que no detecte ni reporte no resultará eficaz, ya que es una utopía sostener que en una empresa no existen conductas irregulares de sus colaboradores.

\section{Resolución}

Si se detecta un incumplimiento, además de sancionar, el compliance debe minimizar o compensar el impacto generado por la conducta irregular. Para ello se deben subsanar las deficiencias detectadas en el programa con la finalidad de evitar la reincidencia, aunque eso signifique la modificación del modelo de prevención, pues las fallas en el funcionamiento deben ser inmediatamente analizadas para mejorar el protocolo $\mathrm{o}$ procedimiento que funcionó defectuosamente. Y es que la vorágine empresarial y los cambios legislativos pueden desfasar rápidamente una actividad comercial hasta demandar una nueva regulación corporativa interna.

Es necesario documentar las etapas de adopción, implementación y funcionamiento del programa de cumplimiento, pues para lograr la exención de responsabilidad, se debe demostrar que es un modelo de prevención adecuado a la naturaleza, riesgos, necesidades y características de la persona jurídica, y que cuenta con medidas de vigilancia y control idóneas para prevenir delitos o para reducir significativamente el riesgo de su comisión. Asimismo, la oficina de cumplimiento debe gozar de independencia y autoridad dentro de la persona jurídica, tener la atribución de solicitar información, ser escuchado por los directivos y consejeros, contar con recursos humanos y materiales adecuados, y constante apoyo de la gerencia general.

\section{Ventajas y criticas}

Es evidente que un compliance eficaz no solo permite que la empresa cumpla con los requerimientos normativos y evite ser sancionada, sino que también genera una mayor rentabilidad y productividad de la empresa, pues al mantener a la alta dirección informada sobre el desempeño de la corporación, se tomarán mejores decisiones comerciales, lo que redunda en el éxito de la empresa como unidad económica productiva. Además, la transparencia en la información que maneja la empresa respecto a sus procedimientos $\mathrm{y}$ protocolos internos incrementa la buena imagen que pueda tener en el mercado frente a accionistas y clientes, generando una mayor valorización de sus acciones.

No obstante, como toda invención humana no está exenta de críticas, puede suceder que los programas de cumplimiento se utilicen como un instrumento de blindaje de la alta dirección de la persona jurídica para evitar la persecución y sanción penal desnaturalizando la razón de ser de esta herramienta.

Por otro lado, un programa de cumplimiento en el que predomine excesivamente la vigilancia y control de sus colaboradores puede generar un clima laboral de desconfianza e inseguridad repercutiendo negativamente en su desempeño y motivación, lo cual a su vez reduciría ostensiblemente su eficiencia.

\section{CONCLUSIONES}

Luego de haber revisado algunas de las más importantes teorías criminológicas aplicables al compliance, se comprende la importancia del enfoque criminológico para analizar mejor la función de este instrumento jurídico en el seno de toda persona jurídica. Este nos permite entender mejor su aplicación práctica y perfeccionar su utilización como mecanismo de prevención penal.

Las teorías invocadas en este trabajo de investigación nos brindan la posibilidad de 
analizar si las leyes relativas al compliance están sustentadas en estudios criminológicos que permiten evaluar si su puesta en vigencia ha cumplido o no con el objetivo que se pretendía alcanzar o, en todo caso, qué correcciones deben efectuarse para que así sea.

Las características criminógenas de la criminalidad empresarial destruyen las bases de un Estado de derecho; por tanto, es necesario adoptar medidas que protejan dichas estructuras democráticas y sus medios de control, que no sean tan solo punitivas, sino sobre todo anticipadoras de los daños sociales que producen los delitos cometidos.

Es así que a través de compliance las personas jurídicas se organizan para cumplir con las leyes y regulaciones que les concierne obedecer; sin embargo, estas se vuelven ineficaces cuando se limitan a definir los procedimientos y las políticas únicamente con el afán de tener formalmente en un papel un modelo de prevención y en realidad no existe el compromiso de generar una cultura de cumplimiento en la persona jurídica. Dicha cultura corporativa de cumplimiento debe buscar por sobre todo promover la integridad como conducta ética en todas las personas que conforman la persona jurídica. El mecanismo del compliance exige que las empresas, en cierto modo, asuman una tarea pública y que se autorregulen con el fin de ponerse al lado del Estado en la tarea de controlar nuevos riesgos, proteger accionistas o consumidores, o evitar hechos delictivos.

\section{REFERENCIAS}

Carnevali, R. (2010). La criminalidad organizada. Una aproximación al derecho penal italiano, en particular la responsabilidad de las personas jurídicas y la confiscación, 16(2), Revista Ius et Praxis, pp. 273-330.

García, P. (2014). Criminal compliance. Lima: Palestra Editores.
García-Pablos de Molina, A. (1994). Criminología. Una introducción a sus fundamentos teóricos para Juristas. Valencia: Tirant lo Blanch.

Ley N. ${ }^{\circ} 27963$, Ley de Unidad de Inteligencia Financiera. (12 de abril de 2002). Recuperado del sitio de internet del Congreso de la República del Perú: http://www2.congreso.gob. pe/sicr/cendocbib/con3_uibd.nsf/58CCE3FD09B5 52BD052579900050600F/\$FILE/4_DECRETO_ SUPREMO_N_018_2006_JUS_Aprueban_Reglamento_de_ta_Ley_27693.pdf

Ley N. ${ }^{\circ}$ 29783, Ley de Seguridad y Salud en el Trabajo. (20 de agosto de 2011). Recuperado del sitio de internet del Ministerio de Trabajo del Perú: http://www.mintra.gob.pe/ normaCompletaSNIL.php?id $=3601$

Ley N. 29783, Ley General del Ambiente. (15 de octubre de 2005). Recuperado del sitio de internet del Congreso de la República del Perú: http://www2.congreso.gob.pe/sicr/ cendocbib/con3 uibd.nsf/58CCE3FD09B552 BD052579900050600F/\$FILE/4_DECRETO_ SUPREMO_N_018_2006_JUS_Aprueban_-

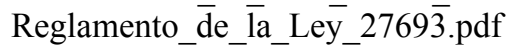

LeyN. ${ }^{\circ} 30424$, Leyqueregulalaresponsabilidad administrativa de las personas jurídicas por el delito de cohecho activo transnacional. (21 de abril de 2016). Recuperado del sitio de internet del diario oficial El Peruano: http://busquedas. elperuano.com.pe/normaslegales/ley-que-regulala-responsabilidad-administrativa-de-las-persley-n-30424-1370638-1/

Silva, J. (2001). La expansión del derecho penal. Aspectos de la política criminal en las sociedades postindustriales. Madrid: Civitas.

Wellner, P. (2005). Effective Compliance Programs and Corporate Criminal Prosecutions. Cardozo Law Review, 27(1). 